\title{
Opioid-induced hyperalgesia is a paradox for perioperative physician
}

\author{
Heeseung Lee \\ Department of Anesthesiology and Pain Medicine, School of Medicine, Ewha Womans University, Seoul, Korea
}

Hyperalgesia is defined as "increased pain from a stimulus that normally provokes pain" by the International Association of the Study of Pain. Therefore, perioperative opioid-induced hyperalgesia $(\mathrm{OIH})$ could be defined as "increased perception of pain after opioid-based anesthesia and surgery". OIH have been identified mainly after remifentanil-based anesthesia in surgical patients. The cumulative, high dose of remifentanil and rapid withdrawal may be factors in remifentanil-induced hyperalgesia.

Although $\mathrm{OIH}$ is a curious concept, the mechanisms of $\mathrm{OIH}$ are not clearly understood. The links between opioid tolerance and $\mathrm{OIH}$ are also obscure, though some tried to adapt their mechanical discrimination recently to their clinical reports $[1,2]$. The mechanisms of OIH have been postulated in two ways [3]. One is the cellular-level adaptation in desensitization, internalization, downregulation and heterodimerization. The others are the system-level adaptations in descending facilitation, upregulation of spinal dynorphins, neuroplasticity in the rostral ventromedial medulla and dorsolateral funiculus of the spinal cord, downregulation of glutamate transporters and activation of $N$-methyl- $D$-aspartate (NMDA) receptors. Multifactorial mechanisms demonstrate that multimodal efforts to attenuate OIH may be necessary to handle this issue in clinical setting. Multimodal efforts to prevent $\mathrm{OIH}$ has been reported, including ketamine [4], nitrous oxide [5], magnesium [6], and pregabalin [7-9]. Moreover, the opioids that are not only $\mu$ opioid receptor-mediated but also another mechanismmediated, such as methadone and buprenorphine, seldom demonstrate OIH. Although a lack of novelty, nothing new in pregabalin can attenuate OIH perioperatively, Lee et al. [10] tried to investigate the changes of threshold of mechanical nociceptive stimuli in each group using Von Frey filaments. They also demonstrated that pregabalin can attenuate $\mathrm{OIH}$ in aspect to not only clinically relevant pain but also mechanically evoked pain. Opioids remain the most powerful pain killers for acute pain management. Opioids are the prerequisite for perioperative analgesia but $\mathrm{OIH}$ can be the other side of the sword. The continuous interest in OIH and optimized treatments for its prevention will increase the quality of perioperative life.

\section{References}

1. Chu LF, D'Arcy N, Brady C, Zamora AK, Young CA, Kim JE, et al. Analgesic tolerance without demonstrable opioid-induced hyperalgesia: A double-blinded, randomized, placebo-controlled trial of sustained release morphine for treatment of chronic non-radicular chronic pain. Pain 2012; 153: 1583-92.

2. Loftus RW, Yeager MP, Clark JA, Brown JR, Abdu WA, Sengupta $\mathrm{DK}$, et al. Intraoperative ketamine reduces perioperative opiate consumption in opiate-dependent patients with chronic back pain undergoing back surgery. Anesthesiology 2010; 113: 639-46.

3. Mao J. Opioid-induced abnormal pain sensitivity: implications in clinical opioid therapy. Pain 2002; 100: 213-7.

4. Joly V, Richebe P, Guignard B, Fletcher D, Maurette P, Sessler DI, et al. Remifentanil-induced postoperative hyperalgesia and its prevention with small-dose ketamine. Anesthesiology 2005; 103: $147-55$.

5. Echevarria G, Elgueta F, Fierro C. Nitrous oxide reduces postoperative opioid-induced hyperalgesia after remifentanil-propofol anaesthesia in humans. Br J Anaesth 2011; 107: 959-65.

6. Song JW, Lee YW, Yoon KB, Park SJ, Shim YH. Magnesium sulfate

Corresponding author: Heeseung Lee, M.D., Ph.D., Department of Anesthesiology and Pain Medicine, Ewha Womans University Mokdong Hospital, 911-1, Mok 5 dong, Yangcheon-gu, Seoul 158-710, Korea. Tel: 82-2-2650-2670, Fax: 82-2-2655-2924, E-mail: leehee@ewha.ac.kr (c) This is an open-access article distributed under the terms of the Creative Commons Attribution Non-Commercial License (http:// creativecommons.org/licenses/by-nc/3.0/), which permits unrestricted non-commercial use, distribution, and reproduction in any medium, provided the original work is properly cited. 
prevents remifentanil-induced postoperative hyperalgesia in patients undergoing thyroidenctomy. Anesth Analg 2011; 113: 390-7.

7. Jo HR, Chae YK, Kim YH, Chai HS, Lee WK, Choi SS, et al. Remifentanil-induced pronociceptive effect and its prevention with pregabalin. Korean J Anesthesiol 2011; 60: 198-204.

8. Bannister K, Sikandar S, Bauer CS, Dolphin AC, Porreca F, Dickenson AH. Pregabalin suppresses spinal neuronal hyperexci- tability and visceral hypersensitivity in the abscence of peripheral pathophysiology. Anesthesiology 2011; 115: 144-52.

9. Zhang J, Ho KY, Wang Y. Efficacy of pregabalin in acute postoperative pain: a meta-analysis. Br J Anaesth 2011; 106: 454-62.

10. Lee C, Lee HW, Kim JN. Effect of oral pregabalin on opioid-induced hyperalgesia in patients undergoing laparo-endoscopic single-site urologic surgery. Korean J Anesthesiol 2013; 64: 19-24. 